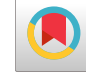

\title{
Review of Iodine Nutrition in Iranian Population in the Past Quarter of Century
}

\author{
Hossein Delshad, ${ }^{1}$ and Fereidoun Azizi ${ }^{1, *}$ \\ ${ }^{1}$ Endocrine Research Center, Research Institute for Endocrine Sciences, Shahid Beheshti University of Medical Sciences, Tehran, IR Iran \\ "Corresponding author: Fereidoun Azizi, Endocrine Research Center, Research Institute for Endocrine Sciences, Shahid Beheshti University of Medical Sciences, Tehran, IR Iran. \\ Tel: +98-2122432500, Fax: +98-2122416264, E-mail: azizi@endocrine.ac.ir
}

Received 2017 February 21; Revised 2017 August 16; Accepted 2017 September 04.

\begin{abstract}
Context: Iodine deficiency is one of the most important health problems worldwide. The overall aim of this study was a narrative review of the past and present status of iodine nutrition in the Iranian population to gather and provide valuable background data in this field for future studies.

Evidence Acquisition: For this narrative literature review study, published internal (SID, Iran doc, Iran medex) and international (Web of knowledge, Pubmed, SCOPUS) source studies were searched using the following medical subject heading terms: Iodine, IDD (iodine deficiency disorders), UIC (urinary iodine concentration), Goiter, IQ (intelligence quotient), thyroid hormone, Iodine and pregnancy, Iodine and breast feeding, as well as Iodized salt, reporting the prevalence of iodine deficiency and iodine nutrition status of different target populations in Iran over 25 years, between 1988 - 2014, were assessed. We found 185 abstracts by literature search, of which, 161 papers that were as case reports, animal study, with lack of regional or national data were excluded after full text evaluation. Finally 24 full papers covering regional or national data on iodine nutrition of the study population were eligible for our review.

Results: Iodine deficiency, as a nutritional problem, had been identified in Iran since 1968. In the years 1987 - 1989, a few studies were done to define the prevalence of iodine deficiency in the country. The first nation-wide survey was performed in 14 provinces. Based on this survey all provinces were suffering of endemic goiter. In 1989, iodine deficiency was recognized as a major problem for community health. In 1990, salt factories began to produce iodized salt and in 1996, the second national survey was performed in 26 provinces. This survey indicated that $40 \%$ of boys and $50 \%$ of girls have goiter, with a median urinary iodine excretion of $205 \mu \mathrm{g} / \mathrm{L}$. The 3rd national survey in 2001 showed that the total goiter rate is $9.8 \%$ and median UIC of $165 \mu \mathrm{g} / \mathrm{L}$. In 2007, the 3th national survey was conducted 17 years after iodized salt consumption by Iranian households. In this study the total goiter rate and median urinary iodine was 5.7\% and $145 \mu \mathrm{g} / \mathrm{L}$, respectively. The 5th national survey conducted in 2013, showed household consumption of iodized salt for all provinces was $98 \%$ and the median urinary iodine of school children was $161 \mu \mathrm{g} / \mathrm{L}$. Following the 5th national survey, the 1st national survey of the iodine status and thyroid function of pregnant women, conducted in 10 provinces in the different region of the country, documented a median UIC for pregnant women of $87.3 \mu \mathrm{g} / \mathrm{L}$, results of this national survey clarified that despite iodine sufficiency of school children in Iran, pregnant women have moderate iodine deficiency and need iodine supplementation. Conclusions: The success of iodine deficiency control program depends on well designed programmatic steps and mandatory iodized salt consumption in certain situations. The iodine intake of school children is sufficient, however, Iranian pregnant women are suffering from moderate iodine deficiency and need iodine supplementation.
\end{abstract}

Keywords: Iodine, Iodine Deficiency Disorders, Iodized Salt, UIC

\section{Context}

As an essential nutrient, iodine plays a major role in thyroid hormone synthesis (1). Inadequate iodine intake affects the physical and mental development of millions of people worldwide (2). Elimination of iodine deficiency is simple and feasible through iodine supplementation $(3,4)$, and since 1960, throughout the years remarkable progress has been witnessed in this field. Methods of prevention have been refined and developed using iodized oil as a prophylactic technique and significant implementation of salt iodization programs have been implemented in many countries. By 1990, just a handful of countries were considered to be iodine sufficient, and today, $70 \%$ of the worlds population are consuming adequate iodized salt (5).

The normal concentration of body iodine is $15-20 \mathrm{~m}$ and the exogenous source of iodine is necessary to maintain this amount in our body (6). Iodine is efficiently ab- 
sorbed from the gut, however, the thyroid gland takesup only $10 \%$ of it. This amount could increase to $80 \%$ in the chronic iodine deficiency state (7). The breast of the mother concentrates iodine in mammary glands to provide iodine for her newborn, $40 \%-45 \%$ of the iodine ingested by the mother appears in breast milk $(8,9)$. The urinary excretion level of iodine $(\mu \mathrm{g} / \mathrm{L})$ is a useful indicator of recent iodine intake. According to the WHO recommendation, urinary iodine excretions between 100 to 199 $\mu \mathrm{g} / \mathrm{L}$ in school-aged children as well as adults, and between 150 to $249 \mu \mathrm{g} / \mathrm{L}$ in pregnant women are considered adequate (10). The daily uptake of iodine by the thyroid gland is $60 \mu \mathrm{g}$, this amount is necessary for adequate thyroid hormone synthesis. Iodine is an essential element of thyroid hormones, it constitutes $65 \%$ and $59 \%$ of the weight of thyroxine and triiodothyronine, respectively. Thyroid hormones regulate numerous physiologic processes in human health. Body growth, neurologic development, and reproductive function are depended to the adequate thyroid hormone during the different stages of life (11). The primary source of iodine for the fetus is maternal iodine, which cross the placenta and provide this essential nutrient to the fetus. The different disturbances resulting from inadequate iodine intake are collectively known as iodine deficiency disorders (IDDs), which was introduced by Basil Hetzel in 1983 (12). Goiter is the most common presentation of iodine deficiency worldwide. According to the WHO recommendation, in iodine sufficient areas, the prevalence of goiter should be less than 5\% (10).

The global program for the elimination of iodine deficiency and brain damage using iodized salt dates back to 1990 when the political support required became available through the World Summit for Children with the support of the UN System, the WHO, and UNICEF. In 1990, WHO estimated that in 130 countries, 2.2 billion people were at risk for IDD; $12 \%$ had goiter, $8 \%$ had some degree of mental impairment due to iodine deficiency, and $2 \%$ were cretinus (13). The number of iodine-sufficient countries has increased from 67 to 112, during the past decade. In 2016, iodine intake was adequate in 102 countries, deficient in 15 countries, and excessive in 10 countries (14). The overall aim of this study was a narrative review of the past and present status of iodine nutrition in the Iranian population to gather and provide valuable background data in this field for future studies.

\section{Methods}

This is a narrative review of iodine nutrition in the Iranian population during the last 30 years. All published internal (SID, Iran doc, Iran medex) and international (Web of knowledge, Pubmed, SCOPUS) source stud- ies were searched using the following medical subject heading terms: Iodine, IDD (iodine deficiency disorders) UIC (urinary iodine concentration), Goiter, IQ (intelligence quotient ), thyroid hormone, Iodine and pregnancy, Iodine and breast feeding, as well as Iodized salt, reporting the prevalence of iodine deficiency and iodine nutrition status of different target populations in Iran over a 25 years, between 1988 - 2014. We found 185 abstracts by literature search, of which, 161 papers that were case reports, animal study, or with lack of regional or national data were excluded after full text evaluation. Finally, 24 full papers covering regional or national data on iodine nutrition of the study population were eligible for our review.

1- History of IDD in Iran:

Thirty years ago our country was severely affected by iodine deficiency and endemic goiter was prevalent in many parts of the country. In 1968, for the first time, it was reported that the prevalence of goiter was between $10 \%$ to $60 \%$ in I.R. Iran (15). Between 1983 - 1984 the endocrine research center and the food technology and nutrition research institute of Shahid Beheshti University of Medical Sciences and many researchers in other provinces conducted a few studies in some provinces, all of which reported goiter to be hyper-endemic (16). The first of these surveys was performed in Shahriar, a town in south west Tehran. A total of 2034 individuals were investigated; of whom $54 \%$ males and $66 \%$ females had goiter (17). In addition 7061 school aged children were surveyed, of whom $74 \%$ girls and $73 \%$ boys had goiter. In another study, the prevalence of goiter in girls was $88 \%$ and in boys $71.5 \%$ in east Tehran (18). In 1985, another survey was performed in KohKilloyeh Boyerahmad, a province in south central Iran. In this study $95 \%$ of women and $87 \%$ of men had goiter (19). From 1987 to 1989, before the salt iodization and iodized oil injection programs, the adverse outcomes of iodine deficiency on different body organs was studied in the capital city Tehran as well as Kiga, Randan, and Keshar, three villages located in northwest Tehran.

The study done by Azizi et al. conducted on school children, with different degrees of iodine deficiency, showed that the prevalence of goiter was severe in Randan with high TSH levels and alterations in thyroid function. The bone and psychomotor age of school children were retarded and all of them had low intellectual quotient (IQ). The severity of iodine deficiency in Tehran was mild and only $15 \%$ of the population had grade 2 goiter without any change in thyroid function and their somatic or psychomotor development was normal. In Zagoon, another village near Tehran, school children had normal thyroid function and normal somatic development, however, their intellectual quotient was less than the school children in Tehran (20). In another study by the same group con- 
ducted 2 years later in school children from 2 villages (Kiga and Keshar) in northwest Tehran as well as 1 school in Tehran, the prevalence of visible goiter was 93\% in children from Kiga with growth retardation and thyrotropinemia in $70 \%$; the prevalence of visible goiter in children from Keshar was $66 \%$ and only $7 \%$ had thyrotropinemia; of school children in Tehran, 22\% had visible goiter, however, their thyroid function test was normal, and UIC was low in all school children from the 3 study areas. The head circumference of children from Kiga and Keshar, was smaller than those from Tehran. A total of $44 \%$ of the children from Kiga, 15\% from Keshar and 2\% from Tehran had hearing deficits revealed by audiometry. Following the Bender Gestalt test performed to examine the psychomotor activity, it was found that the psychomotor age of children was less than their chronological age. There was a positive correlation ( $r$ $=0.331, \mathrm{P}<0.025)$ between pyramidal signs and serum thyrotropin (TSH). On the Raven test, mild impairment of the IQ was detected. In Kiga, 55\% of children had an IQ below 91 and 15\% below 70 (21). Many surveys in other provinces including Khorasan, Rasht, Fars, and Isfahan showed endemic or hyper-endemic goiter. Based on these results, the Ministry of Health and Medical Education in 1988 formed the Iranian national committee for control of IDD (INCCI), following which the first national study was conducted in 14 provinces. In all provinces the goiter was endemic. The UIC of the total study population was below $100 \mu \mathrm{g} / \mathrm{L}$, being less than $20 \mu \mathrm{g} / \mathrm{L}$ in many areas (16). After the first survey was done in Shahriar in 1984, a pilot iodated salt prophylaxis project was initiated and a follow-up study showed an increase in urinary excretion of iodine (22).

2-Control of IDD in Iran:

Iodine deficiency was recognized as a major burden of community health in I.R. Iran in 1989, and production, distribution, and consumption of iodized salt was initiated in 1990; however, the percent of urban and rural households consuming iodized salt until 1993 was only 70\% and 50\%, respectively.

In 1994 the parliament passed the first law where all salts for household use in Iran should be iodinized. Thereafter, household salt consumption increased and today national studies show that over $95 \%$ of the Iranian population is using iodized salt. In 1996, the second national survey showed the total goiter rate to be over $40 \%$ in boys and over $50 \%$ in girls and all school children had justly palpable (grade 1) goiter with adequate UIC (over the amount recommended by WHO/UNICEF/ICCIDD) (23). This survey showed that the IDD elimination program and consumption of iodized salt by Iranian households was very effective and in the year 2000, I.R. Iran was recognized as an iodine sufficient country by WHO-EMRO (24). In 1995, Azizi et al. conducted another survey after 12 years of salt iodization in Shahriar (25). Before iodine supplementation, the goiter prevalence rates were $50 \%$ in men and $70 \%$ in women, however, after iodine supplementation, these rates decreased to $40 \%$ and $51 \%$ in men and women, respectively $(\mathrm{P}<0.001)$. In this study, the decrease in the prevalence of goiter was more prominent in younger individuals; the mean UIC was 76 and $185 \mu \mathrm{g} / \mathrm{L}$ before and after iodine supplementation, respectively. In 1984, before salt iodization, $47.5 \%$ of the population had UIC between 20 to $50 \mu \mathrm{g} / \mathrm{L}$, however, in 1995, 12 years after iodine supplementation, $65 \%$ had urinary iodine between 100 to $250 \mu \mathrm{g} / \mathrm{L}$. In another study, Heydarian et al. determined the goiter rate, serum TSH, TPOAb, and TgAb antibodies, as well as UIC 10 11 years prior to and 5-6 years after national salt iodization in Iran (26). In this study, 465 and 1426 adults from Tehran aged $\geq 20$ years were selected pre- and post-iodization, respectively. Total goiter rates were $65.2 \%$ in pre-iodization (1983 - 1984) vs. 25.2\% post-iodization (1999 - 2000) $(\mathrm{P}<$ 0.0001 ). In 1983 - 1984, 3.2\% had positive TPOAb and $4 \%$ of individuals had positive Tg-Ab; corresponding values were 12.5 and $16.8 \%$ in 1999 - 2000 . Results of this study showed that salt iodization had increased population UIC, however, it was associated with the increase in thyroid autoantibodies without clinically significance change in thyroid function test.

One decade after universal salt iodization, goiter prevalence and urinary iodine concentration (UIC) were assessed among school children in the Gorgan province (27), and goiter was detected in $26.4 \%$ children with the median UIC for all children being $190 \mu \mathrm{g} / \mathrm{L}$; this study also indicated that Gorgan province is an iodine-sufficient area. Rajabian et al. also conducted a before-after preventive trial, to determine the effects of iodized salt in preventing of iodine deficiency disorders in Tabas (a city located in the southern part of the Khorasan province), where the prevalence of goiter in 2150 students, aged 6 - 18 years, had decreased from $34 \%$ to $25 \%$ after 10 years of iodized salt consumption $(\mathrm{P}<0.001)(28)$.

Ten years after universal salt iodization, 2 clinical trials $(29,30)$ reported improved hearing thresholds and IQ scores of school children in the villages of Kiga and Randan. In the year 2000, another study was conducted in Kiga. In this study 212 school children from a sever iodine deficient area, before intervention (1989), 3 years after injection of $480 \mathrm{mg}$ iodized oil (1992) and 7 years after consumption of iodized salt (1999), were selected. Compared to 1989, in 1992 and 1999 the goiter prevalence was significantly low and the rise of serum thyroxine was considerable. Of the school children, $44 \%$ had a mean hearing threshold of $15.8 \pm 5.9$ before iodine supplementation. In 1989,1992 , and $1999,46 \%, 11 \%$, and $10 \%$ of school children had hearing thresholds $>15 \mathrm{Db}$, respectively $(\mathrm{P}<0.001)$ 
(31). Aminorroaya et al. investigated the prevalence of goiter in Isfahan 15 years after universal salt iodization (32). A total of 2,523 Isfahani adults, aged $>20$ years participated in this study of whom, $19 \%$ had goiter, $6.4 \%$ of the non-goitrous, and $18.6 \%$ of goitrous subjects had hypothyroidism. Of non-goitrous and goitrous subjects, $24 \%$ and $33.5 \%$ had positive TPOAb, respectively $(\mathrm{P}=0.03)$; the median UIC was $180 \mu \mathrm{g} / \mathrm{L}$.

In 2001, the national program was evaluated as the third national survey $(33,34)$, in which $9.8 \%$ of school children had grade 1 goiter and their median urinary iodine excretion was $165 \mu \mathrm{g} / \mathrm{L}$.

The mean \pm SD for salt iodine content of households was $32.7 \pm 10.1$ and $33.0 \pm 10.2 \mathrm{ppm}$ in 2001 and in 1996, respectively $(\mathrm{P}=0.57)$.

Recurrence of iodine deficiency in iodine-sufficient areas may be possible (35); to prevent this recurrence, a surveillance program every 5 years on the sustainability of iodine sufficiency is mandatory. In this regard, the fourth national study was conducted in 2007, 17 years after the consumption of iodized salt in Iran $(36,37)$; its results showed that $98 \%$ of households in all provinces consume iodized salt, $5.7 \%$ of schoolchildren had grade 1 goiter, which was significantly lower than previous surveys and median urinary iodine was $145 \mu \mathrm{g} / \mathrm{L}$. The median UIC of school children was $<100 \mu \mathrm{g} / \mathrm{L}$ in 1989; however, it increased to $>100 \mu \mathrm{g} / \mathrm{L}$ by 1996 (Figure 1). The prevalence of goiter rates was $68 \%$ in 1989 ; however, it decreased to $5.7 \%$, in 2007 (Figure 2).

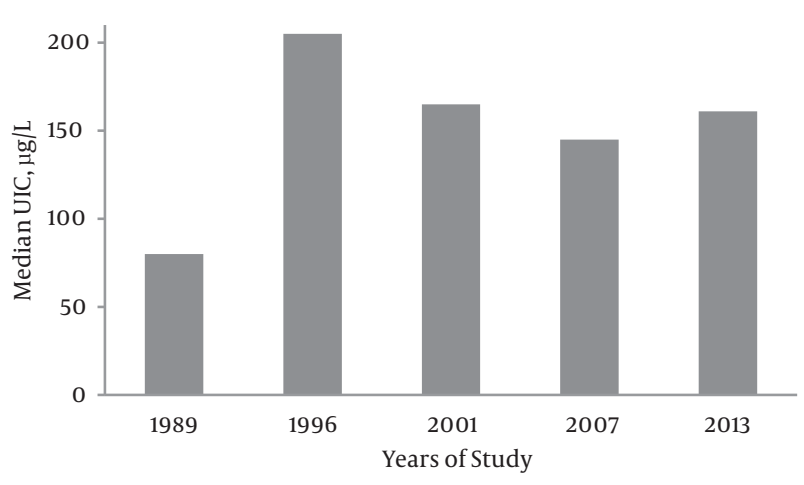

Figure 1. The Trend of Median Urinary Iodine Concentration of Iranian Population From 1989 to 2013 (36)

In 2013, the fifth national survey was conducted in all provinces of the country. In this survey, the median urinary iodine of the school children was determined and household salt iodine content was assayed for quality and quantity control. Iodized salt consumption of households was 98\% for all provinces. The median urinary iodine of school children was $161 \mu \mathrm{g} / \mathrm{L}$ and the mean \pm SD for salt iodine con-

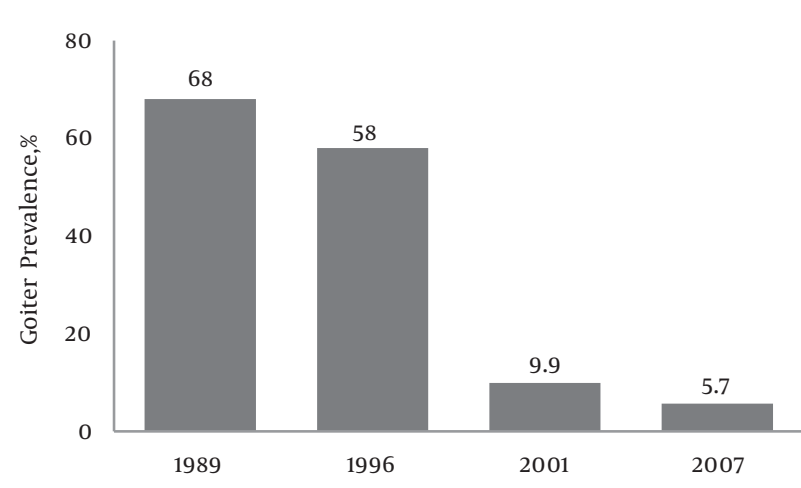

Figure 2. Total Goiter Rate (\%) in 4 National Surveys; 1989 (Before) and 1996, 2001, as Well as 2007 (After) IDD Control Program (37).

tent was $38.6 \pm 10.1 \mathrm{ppm}$ in households and $41.2 \pm 12.7 \mathrm{ppm}$ in factories (unpublished data).

It has been shown in different studies that the median UIC in children does not accurately define normal iodine nutrition in pregnancy, suggesting that even in an iodine-sufficient area, women during pregnancy and lactation need additional iodine. Following the 5th national survey, the 1st national survey assessing iodine intake and thyroid function of pregnant women was performed in 10 provinces of the country in 2014 (38). In this study median UIC of women was $87.3 \mu \mathrm{g} / \mathrm{L}$, it was 92.1, 86.0, and $76.8 \mu \mathrm{g} / \mathrm{L}$, in the 3 trimesters of pregnancy, respectively. Of the women, $9 \%$ had elevated serum TSH (6.6\% subclinical, $2.4 \%$ overt hypothyroidism), $0.6 \%$ had low serum TSH, and $7.6 \%$ had positive TPOAb. Results of this study showed that despite iodine sufficiency of school children in Iran, pregnant women are suffering from moderate iodine deficiency and need iodine supplementation.

Findings of other local studies have also demonstrated that more attention should be paid to iodine intake of pregnant and lactating mother in Iran. A cross- sectional study was conducted by Azizi et al. between 1996 and 1998 . In this study, 403 pregnant women participated from 4 cities i.e Rasht, Ilam, Isfahan, and Tehran and a study of 100 lactating women from Taleghani hospital in Gorgan, Iran in 2003 (39); urinary iodine concentration of $84 \%$ of pregnant women in Rasht city was $\geq 200 \mu \mathrm{g} / \mathrm{L}$, however, it ranged from $45 \%$ to $55 \%$ in the other 3 cities. Overall the urinary iodine concentration was below what was recommended during pregnancy in 51\% of women.

Ainy et al., in a study of Tehranian pregnant women, assessed inter-trimester and seasonal variations in urinary iodine concentration (UIC) (40); there were no seasonal fluctuations in median UIC during pregnancy. It was 193 (19 - 840), 159 (16 - 640), and 141 (16 - 400) $\mu \mathrm{g} / \mathrm{L}$ in the 1st, 2nd, and 3 rd trimesters, respectively $(\mathrm{P}<0.0001)$. More women 
had UIC $<150$ in the 2 nd and the 3rd vs. the 1st trimester of pregnancy. Amouzegar and Azizi, in a study, assessed variations of urinary iodine concentration (UIC) of pregnant and non-pregnant women during 4-week in Tehran, capital city of Iran (41), their urine samples were collected on an every-other-day basis for 4 weeks (i.e., 12 samples for each individual). In this study there was wide variation in UIC values in the same individual among iodine sufficient pregnant and non-pregnant women, indicating that casual UIC is not suitable for assessment of the iodine status of individuals.

A woman needs more iodine during pregnancy and lactation to transfer thyroxine and iodine to the fetus and neonate (42-44). It is believed that in iodine sufficient areas, pregnant women adjust their thyroidal iodine uptake to meet the increased iodine requirement for thyroid hormone production, whereas in iodine deficient regions, such adaptive mechanisms may fail to maintain adequate iodine stores $(45,46)$. However, recently, iodine intake during pregnancy has been reported to be insufficient, even in the areas that had been iodine sufficient for several decades (47-50). The American thyroid association (ATA) recommends that all women receive at least $150 \mu \mathrm{g}$ iodine daily as dietary supplement (51). In agreement with recent guidelines of both the ATA (52) and the endocrine society (53), all pregnant and breastfeeding women need a daily intake of $250 \mu \mathrm{g}$ iodine, both in iodine-deficient and iodine- sufficient areas.

\section{Conclusions}

An excellent sustainable and well-monitored iodine deficiency control program has been arranged by I.R. Iran. Determination of median UIC in school children and the monitoring of the quality of salt are essential for continuing success of iodine sufficiency programs. One of the most important aspects of this work is determination of iodine nutrition of vulnerable subjects, including pregnant women and breastfeeding mothers. The iodine intake of school children is sufficient, however, Iranian pregnant women are suffering from moderate iodine deficiency and need iodine supplementation.

\section{Acknowledgments}

The authors would like to express their appreciation to the investigators and the studies participants of all the provinces of Iran. Authors would also like to acknowledge Ms Niloofar Shiva for critical editing of English grammar and syntax of the manuscript.

\section{References}

1. Wolff J, Chaikoff IL. Plasma inorganic iodide as a homeostatic regulator of thyroid function. J Biol Chem. 1948;174(2):555-64. [PubMed: 18865621].

2. Andersson M, Takkouche B, Egli I, Allen HE, de Benoist B. Current global iodine status and progress over the last decade towards the elimination of iodine deficiency. Bull World Health Organ. 2005;83(7):518-25. [PubMed: 16175826].

3. Hetzel BS, Dunn JT. The iodine deficiency disorders: their nature and prevention. Annu Rev Nutr. 1989;9:21-38. doi: 10.1146/annurev.nu.09.070189.000321. [PubMed: 2669871].

4. Charlton K, Skeaff S. Iodine fortification: why, when, what, how, and who? Curr Opin Clin Nutr Metab Care. 2011;14(6):618-24. doi: 10.1097/MCO.ob013e32834b2b30. [PubMed: 21892078].

5. Zimmermann MB, Andersson M. Assessment of iodine nutrition in populations: past, present, and future. Nutr Rev. 2012;70(10):553-70. doi: 10.1111/j.1753-4887.2012.00528.x. [PubMed: 23035804].

6. Wayne EJ, Koutras DA. Clinical aspects of iodine metabolism. Blackwell Scientific Publications; 1964.

7. Stanbury JB, Brownell GL, Riggs DS, Perinetti H, Itoiz J, Del Castillo EB. Endemic goiter: the adaptation of man to iodine deficiency. Cambridge: Harvard University Press; 1954.

8. Azizi F, Smyth P. Breastfeeding and maternal and infant iodine nutrition. Clin Endocrinol (Oxf). 2009;70(5):803-9. doi: 10.1111/j.13652265.2008.03442.x. [PubMed: 19178515].

9. Laurberg P, Andersen SL. Nutrition: Breast milk-a gateway to iodinedependent brain development. Nat Rev Endocrinol. 2014;10(3):134-5. doi: 10.1038/nrendo.2014.3. [PubMed: 24468649].

10. World Health Organization . Assessment of iodine deficiency disorders and monitoring their elimination. A guide for programe managers. Geneva: World Health Organization; 2007.

11. Morreale de Escobar G, Obregon MJ, Escobar del Rey F. Role of thyroid hormone during early brain development. Eur J Endocrinol. 2004;151 Suppl 3:U25-37. [PubMed: 15554884].

12. Hetzel BS. Iodine deficiency disorders (IDD) and their eradication. Lancet. 1983;2(8359):1126-9. [PubMed: 6138653].

13. Andersson M, Karumbunathan V, Zimmermann MB. Global iodine status in 2011 and trends over the past decade. J Nutr. 2012;142(4):74450. doi: 10.3945/jn.111.149393. [PubMed: 22378324].

14. ICCIDD . Website of the International Council for the Control of Iodine Deficiency Disorders. ICCIDD global network 2015. Available from: http://www.iccidd.org.

15. Emami A, Shahbazi H, Sabzevari M, Gawam Z, Sarkissian N, Hamedi P, et al. Goiter in Iran. Am J Clin Nutr. 1969;22(12):1584-8. [PubMed: 5362485].

16. Azizi F, Kimiagar M, Nafarabadi MT, Yassai M. Current status of iodine deficiency disorders in the Islamic Republic of Iran. Eastern Mediterranean Region Health Services J. 1990(8):23-7.

17. Azizi F, Kimiagar M, Bastani J, Navai L, Ghazanfari F. Evaluation of goiter in Shahriar.J Beheshti Med Sch. 1985;9:75-80.

18. Azizi F, Nafarabadi M, Azartash P, Kimiagar M, Yassai M, Azadeghan M. Evaluation of goiter in east Tehran.J Beheshti Med Sch. 1987;11:41-7.

19. Kimiagar M, Yassai MB, Nafarabadi MT, Samimi B, Azizi F. Endemic goiter in boyer-ahmad. Med J Islamic Republic Iran. 1989;3(1):27-9.

20. Kimiagar M, Azizi F, Nafarabadi M, Yassai M. Iodine deficiency, hypothyroidism and growth retardation near Tehran. Proceeding AOTA Symposium on IDD. Tianjin. .

21. Azizi F, Sarshar A, Nafarabadi M, Ghazi A, Kimiagar M, Noohi S, et al. Impairment of neuromotor and cognitive development in iodine-deficient schoolchildren with normal physical growth. Acta Endocrinol (Copenh). 1993;129(6):501-4. [PubMed: 8109182].

22. Navai L, Fatahi F, Azizi F. Monitoring iodine deficiency following consumption of iodized salt in the 6-12 year-old population in a rural area near Tehran. 28th Annual meeting of the European thyroid Association. Goteborg. . 
23. World Health Organization. Assessment of the iodine deficiency disorders and monitoring their elimination. Geneva: World Health Organization; 2001. pp.1-107.

24. WHO . Regional meeting for the promotion of iodized salt in the Eastern Mediterranean, Middle East and North Africa Region, Dubai, United Arab Emirates. ; 2000.

25. Azizi F, Navai L, Fattahi F. Goiter prevalence, urinary iodine excretion, thyroid function and anti-thyroid function and anti-thyroid antibodies after 12 years of salt iodization in Shahriar, Iran. Int J Vitam Nutr Res. 2002;72(5):291-5. doi: 10.1024/0300-9831.72.5.291. [PubMed:12463103].

26. Heydarian P, Ordookhani A, Azizi F. Goiter rate, serum thyrotropin, thyroid autoantibodies and urinary iodine concentration in Tehranian adults before and after national salt iodization. J Endocrinol Invest. 2007;30(5):404-10. doi: 10.1007/BF03346318. [PubMed: 17598973].

27. Bazrafshan HR, Mohammadian S, Ordookhani A, Farhidmehr F, Hedayati M, Abdolahi N, et al. Prevalence of goiter among schoolchildren from Gorgan, Iran, a decade after national iodine supplementation: association with age, gender, and thyroperoxidase antibodies. $J$ Endocrinol Invest. 2005;28(8):727-33. [PubMed: 16277169].

28. Khajedaluee M, Rajabian R, Seyyednozadi M. Education achievements and goiter size ten years after iodized salt consuming. Int J Prev Med. 2013;4(8):876-80. [PubMed: 24049612].

29. Heydarian P,Azizi F. Thyroid dysfunction and autoantibodies 10 years after implementation of universal salt iodization: Tehran Thyroid Study. Iran J Endocrinol Metabol. 2002;4(4):229-41.

30. Mirmiran P, Salarkia N, Azizi F. Timing of the effect of iodine supplementation on intelligent quotients of schoolchildren. 7th Asia and Oceania Thyroid Association Congress: AOTA. Singapore. .

31. Azizi F, Kalani H, Kimiagar M, Ghazi A, Sarshar A, Nafarabadi M, et al. Physical, neuromotor and intellectual impairment in noncretinous schoolchildren with iodine deficiency. Int J Vitam Nutr Res. 1995;65(3):199-205. [PubMed: 8830000].

32. Aminorroaya A, Amini M, Hovsepian S. Prevalence of goitre in Isfahan, Iran, fifteen years after initiation of universal salt iodization.J Health Popul Nutr. 2010;28(4):351-8. [PubMed: 20824978]

33. Azizi F, Mehran L, Sheikholeslam R, Ordookhani A, Naghavi M, Hedayati M, et al. Sustainability of a well-monitored salt iodization program in Iran: marked reduction in goiter prevalence and eventual normalization of urinary iodine concentrations without alteration in iodine content of salt. J Endocrinol Invest. 2008;31(5):422-31. doi: 10.1007/BF03346386. [PubMed: 18560260].

34. Azizi F, Delshad H, Mehran L, Mirmiran P, Sheikholeslam R, Naghavi $\mathrm{M}$, et al. Marked reduction in goiter prevalence and eventual normalization of urinary iodine concentrations in Iranian schoolchildren, 10 years after universal salt iodination. Iran JEndocrinol Metabol. 2008;10(3):191-203.

35. Zimmermann MB, Wegmuller R, Zeder C, Torresani T, Chaouki $\mathrm{N}$. Rapid relapse of thyroid dysfunction and goiter in school-age children after discontinuation of salt iodization. Am J Clin Nutr. 2004;79(4):642-5. [PubMed:15051609].

36. Delshad H, Amouzegar A, Mirmiran P, Mehran L, Azizi F. Eighteen years of continuously sustained elimination of iodine deficiency in the Islamic Republic of Iran: the vitality of periodic monitoring. Thyroid. 2012;22(4):415-21. doi: 10.1089/thy.2011.0156. [PubMed: 22409203].

37. Delshad H, Mehran L, Azizi F. Appropriate iodine nutrition in Iran: 20 years of success. Acta Med Iran. 2010;48(6):361-6. [PubMed: 21287473].

38. Delshad H, Touhidi M, Abdollahi Z, Hedayati M, Salehi F, Azizi F. Inadequate iodine nutrition of pregnant women in an area of iodine sufficiency. J Endocrinol Invest. 2016;39(7):755-62. doi: 10.1007/s40618016-0438-4. [PubMed: 26951055].
39. Azizi F. Iodine nutrition in pregnancy and lactation in Iran. Pub lic Health Nutr. 2007;10(12A):1596-9. doi: 10.1017/S1368980007360977. [PubMed: 18053284].

40. Ainy E, Ordookhani A, Hedayati M, Azizi F. Assessment of intertrimester and seasonal variations of urinary iodine concentration during pregnancy in an iodine-replete area. Clin Endocrinol. 2007;67(4):577-81.

41. Amouzegar A, Azizi F. Variations of urinary iodine during the first trimester of pregnancy in an iodine-replete area. Comparison with non-pregnant women. Hormones. 2013;12(1):111-8.

42. Smyth PP. Variation in iodine handling during normal pregnancy. Thyroid. 1999;9(7):637-42. doi: 10.1089/thy.1999.9.637. [PubMed: 10447006].

43. Zimmermann MB. Iodine deficiency in pregnancy and the effects of maternal iodine supplementation on the offspring: a review. Am JClin Nutr. 2009;89(2):668S-72S. doi: 10.3945/ajcn.2008.26811C. [PubMed: 19088150].

44. Delange F. Iodine requirements during pregnancy, lactation and the neonatal period and indicators of optimal iodine nutrition. Public Health Nutr. 2007;10(12A):1571-80. doi: 10.1017/S1368980007360941. [PubMed: 18053281] discussion 1581-3.

45. Glinoer D. The regulation of thyroid function during normal preg nancy: importance of the iodine nutrition status. Best Pract Res Clin Endocrinol Metab. 2004;18(2):133-52. doi: 10.1016/j.beem.2004.03.001. [PubMed: 15157832].

46. Gowachirapant S, Winichagoon P, Wyss L, Tong B, Baumgartner J, Melse-Boonstra A, et al. Urinary iodine concentrations indicate iodine deficiency in pregnant Thai women but iodine sufficiency in their school-aged children. J Nutr. 2009;139(6):1169-72. doi: 10.3945/jn.108.100438. [PubMed: 19403711].

47. Leung AM, Pearce EN, Braverman LE. Iodine nutrition in pregnancy and lactation. Endocrinol Metab Clin North Am. 2011;40(4):765-77. doi: 10.1016/j.ecl.2011.08.001. [PubMed: 22108279].

48. Zimmermann MB. Symposium on 'Geographical and geological influences on nutrition': Iodine deficiency in industrialised countries. Proc Nutr Soc. 2010;69(1):133-43. doi:10.1017/S0029665109991819. [PubMed: 19968908].

49. Perrine CG, Herrick K, Serdula MK, Sullivan KM. Some subgroups of reproductive age women in the United States may be at risk for iodine deficiency.J Nutr. 2010;140(8):1489-94. doi:10.3945/jn.109.120147. [PubMed: 20554903].

50. Tahirovic H, Toromanovic A, Balic A, Grbic S, Gnat D. Iodine nutrition status of pregnant women in an iodine-sufficient area. Food Nutr Bull. 2009;30(4):351-4. doi: 10.1177/156482650903000406. [PubMed: 20496625].

51. Public Health Committee of the American Thyroid A, Becker DV Braverman LE, Delange F, Dunn JT, Franklyn JA, et al. Iodine supplementation for pregnancy and lactation-United States and Canada: recommendations of the American Thyroid Association. Thyroid 2006;16(10):949-51. doi:10.1089/thy.2006.16.949. [PubMed:17042677]

52. Stagnaro-Green A, Abalovich M, Alexander E, Azizi F, Mestman J, Negro R, et al. Guidelines of the American Thyroid Association for the diagnosis and management of thyroid disease during pregnancy and postpartum. Thyroid. 2011;21(10):1081-125. doi: 10.1089/thy.2011.0087. [PubMed: 21787128].

53. De Groot L, Abalovich M, Alexander EK, Amino N, Barbour L, Cobin $\mathrm{RH}$, et al. Management of thyroid dysfunction during pregnancy and postpartum: an Endocrine Society clinical practice guideline. J Clin Endocrinol Metab. 2012;97(8):2543-65. doi: 10.1210/jc.2011-2803. [PubMed: 22869843]. 